\title{
O CADE, a Concorrência e a Operação Nestlé-Garoto
}

\author{
José Del Chiaro Ferreira da Rosa' \\ Priscila Brólio Gonçalves ${ }^{2}$
}

\section{Introdução}

O objetivo deste artigo é discutir a decisão proferida pelo CADE por ocasião da análise e julgamento da operação de aquisição da Garoto pela Nestlé. Procuramos demonstrar, ao longo do texto, por que entendemos que a decisão proferida em fevereiro de 2004 foi a mais acertada do ponto de vista da legislação concorrencial brasileira. Em primeiro lugar, fazemos breve digressão sobre a interpretação dada ao art. 54 e seguintes da Lei 8.884/94. Em seguida, discutimos o mérito da decisão do CADE, enfocando seus principais pontos, quais sejam, delimitação dos mercados relevantes, avaliação de competitividade e eficiências. Para concluir, analisamos a adequação da solução estrutural global no caso concreto.

\section{Considerações gerais sobre a exegese do art. 54 e seguintes da Lei 8.884/94}

A Lei 8.884/94 condiciona à aprovação do CADE a eficácia das operações que possam limitar ou de qualquer forma prejudicar a livre concorrência, ou resultar na dominação de mercados relevantes de bens e serviços, dentre as quais os atos de concentração econômica que impliquem a participação de empresa ou grupo de empresas resultante em $20 \%$ de um mercado relevante ou em que qualquer

\footnotetext{
Formado em direito pela Universidade de São Paulo (USP), foi Secretário de Direito Econômico do Ministério da Justiça. Integrante do Instituto dos Advogados de São Paulo, da Associação dos Advogados de São Paulo, além de ser sócio-fundador do Instituto Brasileiro de Estudos da Concorrência e diretor de relaçōes governamentais do Instituto Brasileiro de Estudos da Concorrência (IBRAC).

2 Formada em Direito pela Universidade de São Paulo (USP), Mestre e Doutoranda em Direito Comercial, com especialização em direito concorrencial, pela mesma instituiçāo.
} 
dos participantes tenha registrado faturamento bruto anual de $\mathrm{R} \$ 400$ milhões no último balanço (art. 54, caput e $\$ \$ 3^{\circ}$ e $7^{\circ}$ ).

$\mathrm{O}$ CADE poderá aprovar atos potencialmente restritivos, desde que atendam às seguintes condições previstas no art. $54, \S 1^{\circ}$, cumulativamente:

(i) propiciem aumento de produtividade, melhoria da qualidade de bens ou serviços, ou eficiência e desenvolvimento tecnológico ou econômico;

(ii) os benefícios decorrentes sejam distribuídos eqüitativamente entre os seus participantes, de um lado, e os consumidores ou usuários finais, de outro;

(iii) não impliquem eliminação da concorrência em parte substancial de mercado relevante de bens ou serviços; e

(iv) sejam observados os limites estritamente necessários para atingir os objetivos visados.

A única exceção encontra-se prevista no $\$ 2^{\circ}$ do art. 54 , que estabelece que a operação poderá ser aprovada com o atendimento de pelo menos três dos incisos do $\$ 1^{\circ}$, caso ela seja de "interesse da economia nacional e do bem comum", porém "desde que não implique prejuízo ao consumidor ou usuário final".

As operações que apresentarem caráter limitativo da concorrência, preenchendo, porém, as condiçóes mencionadas acima, poderāo ser aprovadas com restriçōes, cabendo ao CADE, com o objetivo de assegurar o cumprimento das condições estabelecidas, celebrar com as partes um Compromisso de Desempenho, nos termos do que dispõe o art. 58 da Lei 8.884/94:

"O Plenário do CADE definirá compromissos de desempenho para os interessados que submetam atos a exame na forma do art. 54 , de modo a assegurar o cumprimento das condições estabelecidas no $\$ 1^{\circ}$ do referido artigo" (nossos grifos).

Em outras palavras, as concentrações econômicas que não preencherem os requisitos previstos no art. $54, \mathbb{S} \$ 1^{\circ}$ e $2^{\circ}$, da Lei $8.884 / 94$, ou seja, que eliminarem substancialmente a concorrência em determinado mercado relevante, propiciando efeitos líquidos negativos sobre o bem-estar social, não podem ser aprovadas, afastando-se, inclusive, a possibilidade de celebração de um Compromisso de Desempenho. ${ }^{3}$

É importante observar que, no sistema jurídico brasileiro, a existência de eficiências (art. $54, \mathbb{\$} 1^{\circ}$, inciso $i$ ) não justifica, por si só, a aprovação de operações com efeitos nocivos

\footnotetext{
3 Há situações, ainda, em que desinvestimentos parciais ( $v . g .$, a alienaçāo de ativos a terceiros) sāo suficientes para neutralizar os efeitos anticompetitivos oriundos do Ato de Concentração. Embora muitos enquadrem tal hipótese na categoria "aprovação da operaçāo" (com restrições), sendo esta terminologia adotada pelo próprio CADE em suas decisões, preferimos caracterizá-la como "reestruturação", já que, a rigor, a operação aprovada não é exatamente aquela que foi originalmente submetida ao Sistema Brasileiro de Defesa da Concorrência. Voltaremos a esse aspecto no item 3.
} 
para a concorrência. É imperioso que tais eficiências compensem os impactos negativos, que sejam repassadas aos usuários finais e, principalmente, que não haja eliminação de parcela substancial da concorrência.

Verifica-se, destarte, que o legislador brasileiro fez uma opção muito clara pela concorrência, erigindo-a, inclusive, a princípio constitucional e fundamento da ordem econômica, cujo objetivo é "assegurar a todos existência digna conforme os ditames da justiça social" (Constituição Federal, art. 170, caput).

A "não eliminação da concorrência em parte substancial do mercado" não foi uma opção adotada somente pelo legislador brasileiro (constituinte e ordinário); pelo contrário, a maioria dos países do mundo privilegia a livre concorrência ${ }^{4}$ em detrimento das eficiências geradas pela concentração do poder econômico, até porque, a partir de certo nível de concentração de mercado, a perda de concorrência deixa de ser compensável por ganhos de eficiência produtiva e/ou alocativa. Além disso, ainda que tais eficiências existam, elas dificilmente serão compartilhadas com os consumidores.

Na União Européia, o Tratado de Roma contém dispositivos muito semelhantes ao inciso III do $\$ 1^{\circ}$ do art. 54 da Lei Antitruste Brasileira. Com efeito, enquanto o parágrafo primeiro do art. 81 do referido Tratado considera "incompativeis com o mercado comum e proibidos todos os acordos entre empresas, todas as decisóes de associaf̧ões de empresas e todas as práticas concertadas que sejam suscetiveis de afetar o comércio entre os Estados-membros e que tenham por objetivo ou efeito impedir, restringir ou falsear a concorrência no mercado comum", o parágrafo terceiro excepciona as práticas que "contribuam para melhorar a produção ou a distribuição dos produtos ou para promover o progresso técnico ou econômico, contanto que aos utilizadores se reserve uma parte eqüitativa do lucro dai resultante", bem como que tais práticas:

“a) Não imponham às empresas em causa quaisquer restrições que não sejam indispensáveis à consecução desses objetivos;

b) nem dêem a essas empresas a possibilidade de eliminar a concorrência relativamente a uma parte substancial dos produtos em causa."

De forma semelhante dispōe o Clayton Act norte-americano, em sua Seção 7 , destacando-se os seguintes trechos que evidenciam a proibição de operaçōes que possam substancialmente reduzir a concorrência ou que tendam a criar um monopólio:

"Nenhuma pessoa envolvida com o comércio ou com qualquer atividade que afete o comércio poderá adquirir, direta ou indiretamente, a totalidade ou parte das açôes ou outras participações no capital, bem como nenhuma pessoa sujeita à jurisdição da Comissão Federal de Comércio (Federal Trade Commission) poderá

\footnotetext{
4 A esse respeito, vide, por exemplo, Jonathan B. BAKER (The case for antitrust enforcement, Journal of Economic Perspectives, Fall 2003). No Brasil: Jorge FAGUNDES (Fundamentos econômicos das politicas de defesa da concorrência: eficiência econômica e distribuição de renda em análises antitruste, São Paulo, Singular, 2003) e Cleveland Prates TEIXEIRA (Política de defesa da concorrência e desenvolvimento, O Estado de S. Paulo, ediçāo de 8.11.2003).
} 
adquirir a totalidade ou parte dos ativos, de outra pessoa envolvida com o comércio ou com qualquer atividade que afete o comércio, nos casos em que, qualquer que seja o ramo de comércio ou de atividade que afete o comércio em qualquer localidade no país, o efeito de tal aquisição possa ser a redução substancial da concorrência ou uma tendência à criação de monopólio. Nenhuma pessoa envolvida com o comércio ou com qualquer atividade que afete o comércio poderá adquirir, direta ou indiretamente, a totalidade ou parte das ações ou outras participações no capital, bem como nenhuma pessoa sujeita à jurisdição da Comissão Federal de Comércio (Federal Trade Commission) poderá adquirir a totalidade ou parte dos ativos, de outra pessoa envolvida com o comércio ou com qualquer atividade que afete o comércio, nos casos em que, qualquer que seja o ramo de comércio ou de atividade que afete o comércio em qualquer localidade no país, o efeito de tal aquisição, de tais ações ou ativos, ou do uso de tais ações por meio de voto, da outorga de procuração ou de qualquer outra maneira, possa ser a redução substancial da concorrência ou uma tendência à criação de um monopólio" (tradução livre). ${ }^{5}$

É verdade que, no Brasil, ao contrário do que ocorre na maioria dos países com forte tradição antitruste, ainda se permite que a apreciação de atos de concentração ocorra posteriormente à sua realização. Tal circunstância, porém, não tem o condāo de impedir a desaprovação de atos anticompetitivos. Isso porque:

(i) conforme dispõe expressamente o texto legal, se os atos de concentração não forem realizados sob condição suspensiva ou deles já tiverem decorrido efeitos perante terceiros, o CADE, se concluir pela sua não aprovação, determinará as providências cabíveis no sentido de que sejam desconstituídos, total ou parcialmente, independentemente da responsabilidade civil por perdas e danos eventualmente causados a terceiros (Lei 8.884/94, art. 54, $\$ 9^{\circ}$ );

(ii) as medidas cautelares no âmbito do $\mathrm{CADE}$ e, mais recentemente, o instituto do Acordo de Preservação de Reversibilidade de Operação (APRO) podem ser adotados preventivamente para garantir a manutenção do status quo anterior à operação, preservando as condições de mercado e prevenindo mudanças irreversíveis ou de dificil reversibilidade que poderiam ocorrer na sua estrutura até o julgamento final do

\footnotetext{
5 No original: "no person engaged in commerce or in any activity affecting commerce shall acquire, directly or indirectly, the whole or any part of the stock or other share capital and no person subject to the jurisdiction of the Federal Trade Commission shall acquire the whole or any part of the assets of another person engaged in commerce or in any activity affecting commerce, where in any line of commerce or in any activity affecting commerce in any section of the country, the effect of such acquisition may be substantially to lessen competition, or to tend to create a monopoly. No person shall acquire, directly or indirectly, the whole or any part of the stock or other share capital and no person subject to the jurisdiction of the Federal Trade Commission shall acquire the whole or any part of the assets of another person engaged in commerce or in any activity affecting commerce, where in any line of commerce or in any activity affecting commerce in any section of the country, the effect of such acquisition, of such stocks or assets, or the use of such stock by the voting or granting of proxies or otherwise, may be substantially to lessen competition, or to tend to create a monopoly."
} 
Ato de Concentração, evitando o risco de tornar ineficaz o resultado final do mesmo.

Além disso, a lei prevê a possibilidade de que os atos de concentração econômica sejam submetidos previamente ao Sistema Brasileiro de Defesa da Concorrência. Assim, as partes que antevêem e consideram os riscos de que determinada operação entre elas seja desaprovada pelas autoridades antitruste, podem contornar facilmente essa incerteza por meio da inserção de cláusulas suspensivas, inclusive condicionando a concretização do negócio à aprovação do CADE. Caso contrário, assumem sponte propria o risco de desaprovação e desfazimento da operação.

Passamos, a seguir, à análise da decisão proferida no caso Nestlé-Garoto, a partir das considerações apresentadas.

\section{O acerto da decisão proferida pelo CADE no caso Nestlé-Garoto}

Em fevereiro de 2004, acompanhando as conclusōes dos pareceres da Secretaria de Acompanhamento Econômico (SEAE) do Ministério da Fazenda, da Secretaria de Direito Econômico (SDE) do Ministério da Justiça e de sua Procuradoria, o CADE, por 5 (cinco) votos a 1 (um), determinou a desconstituição total da operação consistente na compra da Garoto pela Nestlé. Na verdade, a Nestlé deveria alienar a Garoto a um terceiro que não detivesse participação de mercado igual ou superior a $20 \%$ na indústria brasileira de chocolates.

Em apertada síntese, o CADE entendeu que a aquisição da Garoto pela Nestlé acarretava elevada concentração econômica nos mercados de chocolates sob todas as formas e coberturas de chocolates, fato este que, somado à existência de elevadas barreiras à entrada de novos concorrentes e à ausência de efetiva rivalidade em tais mercados após a operação, permitiria o exercício de poder de mercado, unilateral ou coordenado, ${ }^{7}$ por parte da empresa resultante.

As eficiências apresentadas pela Nestlé não foram reputadas suficientes para compensar os efeitos deletérios sobre a concorrência oriundos da operação proposta, que acabou sendo rejeitada in totum.

\footnotetext{
6 Por ocasião da elaboração deste artigo, a decisão do CADE, confirmada pelo próprio órgão em outubro de 2004, encontrava-se suspensa por decisão judicial.

7 Ainda que determinada operação não permita que a empresa resultante exerça unilateralmente poder de mercado, ela pode acarretar efeitos anticompetitivos por aumentar a probabilidade de exercício coordenado de poder de mercado. Ou seja, a empresa nāo é capaz de, sozinha, reduzir o bem-estar social, porém tal resultado é esperado diante da provável acomodação dos demais concorrentes que, dependendo das circunstâncias, tenderāo a elevar seus próprios preços em caso de um aumento dos preços da empresa fusionada. A esse respeito, vide D. SCHEFFMAN e M. COLEMAN, Quantitative analyses of potential competitive effects from a merger, 2003. Disponivel em: <www.ftc.gov/be/quantmergeranalysis.pdf $>$.
} 
O objetivo deste artigo é demonstrar que a decisāo do CADE é irreparável em termos técnicos.

A fim de justificar que a operação por elas proposta seria passivel de aprovação à luz da Lei 8.884/94, Nestlé e Garoto apoiaram-se em três grupos de argumentos.

Em primeiro lugar, alegaram que a operação não geraria concentração excessiva, seja porque o mercado relevante material seria muito mais amplo do que chocolates, abrangendo diversas guloseimas (sorvetes, balas, bolachas etc.), seja porque, além dos produtores industriais, haveria inúmeros fabricantes artesanais, diluindo as participaçōes de mercado das requerentes da operação.

Em segundo lugar, sustentaram Nestlé e Garoto que a operação, ainda que implicasse elevada concentração em termos de participação de mercado, não teria o condāo de, efetivamente, criar condiçōes para o exercício de poder econômico em detrimento da concorrência. Em outras palavras, a despeito da eliminação de um concorrente efetivo (a Garoto), a concorrência continuaria, segundo as requerentes, operando sem obstáculos, e os consumidores não seriam prejudicados com aumentos de preços. Nesse contexto, defendiam as requerentes que as barreiras à entrada nos mercados não eram substanciais e, principalmente, que $o$ grau de rivalidade após a aquisição da Garoto pela Nestlé continuaria elevado, em virtude da permanência da Lacta como importante concorrente (e disciplinador) da empresa resultante da operação, bem como da existência de uma franja de mercado, integrada por empresas com participações pequenas, mas que poderiam expandir-se caso houvesse um aumento nos preços dos produtos.

Por fim, as requerentes argüiram que a operação geraria um sem-número de eficiências - descritas em estudos e pareceres que não são de conhecimento público em sua integralidade - e que as mesmas compensariam eventuais prejuízos causados pela operação. Ou seja, o balanço concorrencial da aquisição da Garoto pela Nestlé seria positivo, justificando a aprovação da operação pelas autoridades de defesa da concorrência. Aliada a este argumento, havia a idéia de que a Garoto encontrava-se em dificuldades financeiras, com risco de fechamento.

Abordaremos separadamente os três grupos de argumentos, à luz da decisão do CADE.

\section{I Mercados relevantes}

A definição dos mercados relevantes (ou seja, os limites do "espaço" onde se dá a concorrência entre ofertantes de produtos ou serviços), nos seus aspectos material e geográfico, é etapa fundamental da análise antitruste de atos de concentração econômica. ${ }^{8}$ Caso não se configure a criação ou a incrementação do poder de mercado, a operação não gera preocupação sob a ótica concorrencial.

8 A esse respeito, vide P. A. GEROSKI e R. GRIFFITH, Identifying anti-trust markets. In: NEUMANN, M.; WEIGAND, J. International Handbook of Competition, Edgard Elgar, 2003. 
Geralmente, a definição dos mercados relevantes é efetuada pela aplicação do teste do monopolista hipotético, que procura medir quais os efeitos sobre a lucratividade de um possível monopolista de um pequeno, porém significativo (entre 5 e 15\%) e não transitório aumento de preços. Se tal aumento não implicar uma substituição ${ }^{9}$ do produto/serviço ou da área geográfica pelo lado da demanda (percentual substancial de consumidores troca de produto ou de área) ou pelo lado da oferta (outros ofertantes ou outras áreas passam a abastecer o mercado), ao ponto de impedir que ele seja lucrativo, tem-se aí um mercado relevante. Caso contrário, há que se expandir a base de produtos/serviços ou de áreas geográficas até que o aumento seja lucrativo.

No caso concreto, estudos de elasticidades (baseados em econometria e outros métodos) e pareceres apresentados pelas próprias Requerentes Nestlé e Garoto, aplicando os fundamentos do teste do monopolista hipotético, afastaram a delimitação mais ampla do mercado relevante material como "guloseimas". Assim, as próprias empresas abandonaram a sua proposta inicial para os mercados relevantes, mantendo, porém, a argumentação de que os produtores artesanais (ou fabricantes de chocolates não industrializados) integrariam o mercado.

Quanto a estes, no entanto, apurou-se que não tinham escala (capacidade produtiva) suficiente, logística de distribuição, marca(s) conhecida(s) nacionalmente ou capacidade financeira para viabilizar a produçâo e a venda de grandes volumes, e concorrer efetivamente com os produtores industriais, influenciando os preços. Tais circunstâncias já justificariam a sua exclusão dos mercados relevantes.

Além disso, ficou comprovado que os produtores artesanais de chocolate dependiam da Nestlé e da Garoto, as duas principais fornecedoras da matéria-prima cobertura de chocolates, ${ }^{10}$ respondendo juntas por $88,5 \%$ das vendas nacionais desse insumo.

Desse modo, foi correta a decisão do CADE no sentido de excluir as vendas de tais agentes econômicos (de todo modo pequenas) do cômputo das vendas totais de chocolates e definir o mercado relevante de produto como "chocolates industrializados", ao lado do mercado de coberturas, como visto também afetado substancialmente pela operação.

Não merece reparo, conseqüentemente, a conclusão de que as concentrações geradas pela aquisição da Garoto pela Nestlé são significativas, superando, em

\footnotetext{
9 Nos termos da Resoluçāo CADE 20/99, Anexo II, parte B, item 2.1, "a possibilidade de substituif̧ão constitui a variável chave na identificação do mercado relevante, uma vez que a livre concorrência depende da possibilidade do exercicio de escolha por parte dos consumidores. Assim, um mercado relevante, em sua dimensão produto, compreende todos os produtos ou serviços considerados substituiveis entre si pelo consumidor devido às duas características, preços e utilizą̧ão. Por sua vez, em sua dimensāo geográfica, um mercado relevante compreende a área em que as empresas ofertam e procuram produtos/serviços em condį̧ōes de concorrência suficientemente homogêneas em termos de preços, preferências dos consumidores e caracteristicas dos produtos e serviços".

10 Os chocolates artesanais sāo em grande parte produzidos à base de coberturas, sólidas ou líquidas, adquiridas junto à Nestlé, à Garoto e à Arcor. A Lacta produz cobertura de chocolates apenas para consumo cativo. Pouquíssimos fabricantes artesanais produzem a sua própria cobertura de chocolate, à base de pasta de cacau.
} 
muito, o patamar de $20 \%$, percentual a partir do qual a existência de posição dominante é legalmente presumida.

\section{Mercado relevante nacional de chocolates industrializados sob todas as formas}

\begin{tabular}{|c|c|}
\hline Empresa & $\begin{array}{c}\text { Participação percentual com base no fatura- } \\
\text { mento (2001) }\end{array}$ \\
\hline Nestlé & $33,94 \%$ \\
\hline Garoto & $24,47 \%$ \\
\hline Kraft (Lacta) & \\
\hline Ferrero & $33,15 \%$ \\
\hline Arcor & $3,40 \%$ \\
\hline Outros & $3,40 \%$ \\
\hline
\end{tabular}

Fonte: Parecer da SEAE e voto do Conselheiro relator Thompson de Almeida Andrade.

Mercado relevante nacional de coberturas de chocolate

\begin{tabular}{|c|c|}
\hline Empresa & $\begin{array}{c}\text { Participação percentual } \\
\text { com base no faturamento }\end{array}$ \\
\hline Nestlé & $22.1 \%$ \\
\hline Garoto & $66.4 \%$ \\
\hline Arcor & $11,4 \%$ \\
\hline
\end{tabular}

Fonte: Parecer da SEAE e voto do Conselheiro relator Thompson de Almeida Andrade.

\subsection{Barreiras à entrada e rivalidade}

A avaliação dos efeitos concorrenciais associados a uma determinada operação não se resume à análise de participações de mercado. Se assim fosse, o trabalho desenvolvido pelo CADE, uma vez definido(s) o(s) mercado(s) relevante(s), limitar-se-ia a operaçōes matemáticas simples e não seria necessário que os Conselheiros do CADE fossem escolhidos entre cidadãos de "notório saber jurídico ou econômico" (Lei 8.884/94, art. $4^{\circ}$ ).

Ainda que um ato de concentração resulte em elevada concentração em termos de market share, isso não significa que haverá limitação à concorrência ou 
dominaçāo de mercado após a operação. " Se o mercado for contestável, ${ }^{12}$ os compradores possuírem substancial poder de barganha ou se persistir um elevado grau de rivalidade entre os seus participantes (os concorrentes remanescentes), os preços tenderāo a se manter em patamares competitivos.

No caso concreto, as requerentes Nestlé e Garoto procuraram demonstrar que, a despeito da eliminação de um concorrente efetivo, a operação não geraria prejuízos à concorrência. Isso porque as barreiras à entrada nos mercados não seriam substanciais e o grau de rivalidade pós-aquisição continuaria elevado, em virtude da permanência da Lacta como importante concorrente efetivo da empresa fusionada, além das empresas integrantes da franja (que poderiam ampliar suas participaçōes caso houvesse um aumento nos preços dos produtos).

Apurou-se, no entanto, que as barreiras à entrada nos mercados relevantes são elevadas.

No mercado de chocolates sob todas as formas, os investimentos mínimos necessários para a instalação de uma fábrica de chocolates (duas ou três linhas de produção) estão em torno de US $\$ 50$ milhōes (sem incluir os investimentos em distribuição e marca), e o período necessário para tanto é de 2 a 3 anos (incluído o tempo necessário para a formação de uma rede de distribuição em escala nacional e à fixação da marca).

Além disso, a escala mínima de produção é de 30.000 ton./ano, concentrada em duas ou três linhas de produtos, representando cerca de $19 \%$ do consumo

\footnotetext{
11 Segundo Paula FORGIONI, "é fato que a posiçāo dominante deriva não da parcela de mercado de que o agente é titular, mas sim do poder econômico que detém e que lhe permite independência e indiferença em relaçāo ao comportamento de outros agentes, colocando-lhe a salvo de pressōes concorrenciais. Nāo basta, pois, a determinaçāo da parcela de mercado detida pelo agente econômico para se mesurar seu poder, ou seja, seu market power, porque, ainda que titular de parcela não substancial do mercado, pode ter a capacidade, por exemplo, de impor preços, detendo poder econômico que the assegura a posiçāo dominante. Esse problema é disciplinado pela Lei Antitruste brasileira. Com efeito, a conjugação dos $\$ S 2^{\circ} e 3^{\circ}$ do art. 20 da Lei 8.884, de 1994, diz ser presumida a existência de posifão dominante nos casos em que a parcela do mercado relevante detida pelo agente é da ordem de $20 \%$. Assim, nāo obstante esses dispositivos demonstrem que nossa lei optou pelo critério do market share, ao mesmo tempo é acolhido o critério de market power. A presunçāo de que trata o $\int 2^{\circ}$ do art. 20 é, pois, iuris tantum" (Os fundamentos do antitruste, 2. ed., São Paulo: Revista dos Tribunais, 2005, p. 332-333). No mesmo sentido, Neide Teresinha MALARD esclarece que "[o] poder de mercado ou a posição dominante de uma empresa costumava ser aferida em termos de sua participação relativa no mercado", sendo certo, no entanto, que, "[a]tualmente, em todos os sistemas juridicos, a participação relativa é apenas um dentre os vários fatores a serem considerados na verificą̧āo do poder econômico de uma empresa. Os demais dizem respeito à estrutura e ao desempenho do mercado e à conduta das empresas que dele participam. Adota-se, assim, uma noção relativa de dominaf̧ão e não mais absoluta. A participação relativa é o ponto de partida da avaliaf̧ão, e não de chegada, pois pode subestimar o impacto concorrencial futuro" (voto proferido nos autos do Pedido de Reapreciação do Ato de Concentração $n^{\circ}$ 16/94, em que figurava como Requerente a Siderúrgica Laisa S.A.).

12 A teoria dos mercados contestáveis, desenvolvida por BAUMOL, reza que, presentes alguns requisitos - quais sejam, entrada livre (não há custos de entrada ou barreiras), inércia (empresas estabelecidas não reagem imediatamente a reduçōes de preços), e saída sem custos (custos e investimentos assumidos são reversíveis, ou seja, não há sunk costs) - não há como exercer poder de mercado (já que aumentos de preços não serão lucrativos). A simples ameaça de entrada é suficiente para disciplinar os players, mesmo nos mercados concentrados. Evidentemente, nāo há mercados perfeitamente contestáveis, mas o grau de contestabilidade dos mercados pode variar significativamente.
} 
nacional anual de chocolates como um todo (consumo este que, aliás, encontra-se estagnado nos últimos anos).

Nāo fossem suficientes as circunstâncias arroladas nos parágrafos anteriores, ainda existem fidelidade à marca ${ }^{13}$ e segredos industriais relativos às receitas dos chocolates, sendo certo que o sabor e a preferência dos consumidores são fatores relevantes.

Por fim, a montagem de uma rede capilarizada de distribuição é fator crucial para o sucesso dos produtores de chocolates, representando mais um obstáculo à entrada de novos fabricantes industriais de chocolates em escala nacional no Brasil.

No mercado relevante de coberturas, por sua vez, as barreiras à entrada relacionam-se à escala mínima de produção (40.000 ton./ano) e aos investimentos mínimos necessários para a montagem de uma planta ( $\mathrm{R} \$ 50$ milhões). O Conselheiro Thompson de Almeida Andrade considerou que um pequeno produtor de chocolate industrial poderia operar com escala de $3.600 \mathrm{t} /$ ano (para isso investindo $\mathrm{R} \$ 2$ milhões em 12 meses), porém não influenciaria a fixação dos preços pela líder Nestlé-Garoto. Ponderou, ainda, que economias de escala e de escopo obtidas por Nestlé, Garoto e Arcor na produção de coberturas muito provavelmente impediriam a entrada ou permanência de pequenos produtores, na medida em que não havia nenhum no mercado à época de seu voto.

Quanto à rivalidade pós-operação, ficou demonstrado que, à exceção da Kraft (Lacta), os demais fabricantes industriais de chocolates atuantes no Brasil (Mars, Hershey's, Arcor, Ferrero e Neugebauer, multinacionais com participaçōes expressivas em outros mercados) não tinham condiçōes de reagir ao exercício de poder de mercado por parte da empresa fusionada, por não disporem de capacidade de vendas (produção, distribuição e/ou marcas) suficientemente elevada a ponto de gerarem efetiva rivalidade.

Por seu turno, a Kraft, única empresa em condições de reagir ao exercício de poder de mercado por parte da Nestlé, não possuía ociosidade suficiente para elevar sua oferta de chocolates no curto prazo. Mesmo que tal capacidade existisse, o comportamento racional da Kraft, dada a estrutura do(s) mercado(s) em tela e a participação da empresa resultante da operação, seria de seguir a estratégia de preços determinada pela líder. Isso não significa que a Kraft agiria em conluio com a empresa fusionada, mas simplesmente que, em função das interaçōes estratégicas repetidas (jogos dinâmicos) em um mercado praticamente duopolizado, a empresa maximizaria seus lucros mediante uma atitude cooperativa (liderança de preços, por exemplo), não baseada em acordos formais (v. g., cartel).

\footnotetext{
É de se observar que os investimentos (sunk costs) para lançar uma nova marca no mercado giram em torno de $\mathrm{R} \$ 10$ milhões, sendo certo que as empresas líderes são obrigadas a gastar entre $6 \%$ e $10 \%$ de seu faturamento líquido por ano em propaganda e marketing para se manterem competitivas.
} 
Além disso, havia evidências de que a Garoto comportava-se no mercado de chocolates industrializados como uma maverick firm. ${ }^{14}$ Segundo o parecer da Tendências, juntado aos autos pela Kraft, "a queda verificada nos últimos anos nos preços da Nestlé em relação aos da Lacta e da Garoto em alguns segmentos, mostra que a Nestlé vinha brigando para manter sua posição no mercado com uma redução de preços. Dado que para a Lacta não teria sentido uma estratégia mais agressiva de prę̧os (essa empresa não podia expandir volumes), conclui-se que o reposicionamento da Nestlé deve-se à maior agressividade da Garoto. Tendo adquirido justamente esse fabricante, ela não precisa mais fazer isto e pode praticar um movimento inverso, aumentando os preços médios". ${ }^{15}$ Essa análise, porém, não foi aprofundada nos votos vencedores.

\subsection{Eficiências insuficientes}

Diversas simulações realizadas durante a instrução do ato de concentração sugeriam que a aquisição da Garoto pela Nestlé resultaria em aumentos de preços após a operação (entre $8 \%$ e $20 \%$ após a operação, dependendo da segmentação do(s) mercado(s) relevante(s) e das elasticidades empregadas nas simulações).

Na verdade, a SDE constatou que "os efeitos da concentração já se fazem sentir no mercado", uma vez que "de março de 2002 até o presente momento, houve substancial aumento dos prȩ̧os da cobertura sólida ofertada pelas Requerentes", sendo certo que "a empresa Arcor seguiu os aumentos praticados pela empresa concentrada", tendo em vista a sua pequena capacidade ociosa.

Por seu turno, o Procon do Estado de Goiás apurou a elevação dos preços médios dos ovos de Páscoa de todas as marcas pesquisadas (Nestlé, Garoto, Lacta e Arcor) de 50,43\% em 2003, com relação ao ano anterior. ${ }^{16}$

\footnotetext{
14 Maverick firms são empresas que possuem maiores incentivos econômicos para desviar-se dos padrōes de comportamento coordenado relativamente às suas rivais. Tal definiçāo consta das Merger Guidelines norte-americanas de 1992, citadas no artigo de Jonathan BAKER: "a maverick firm is described as one with "a greater economic incentive to deviate from the terms of coordination than do most of [its] rivals" (Mavericks, mergers and exclusion: proving coordinated competitive effects under the antitrust laws, New York University Law Review, v. 77:135, April 2002). Desse modo, as empresas maverick são particularmente importantes para a natureza ou a intensidade da competição no mercado, desproporcionalmente ao seu tamanho ou participação no mercado, forçando os demais ofertantes de um produto a concorrer de forma mais agressiva. Nas palavras de D. SCHEFFMAN e M. COLEMAN, "the maverick may have been very disruptive by attempting to expand share - lowering prices, trying to win customers from competitors and/or expanding capacity - and this behavior has caused other competitors to compete more aggressively and may have undermined their ability to coordinate. A merger that removes this maverick may, as a result, significantly chance the nature and intensity of competition, and higher prices may result as all firms compete less aggressively" (Quantitative analyses of potential competitive effects from a merger, 2003. Disponivel em: <www.ftc.gov/ be/quantmergeranalysis.pdf $>$ ).

15 Trecho extraído da conclusão do parecer da Tendências, fl. 4021 dos autos.

16 Não se tem notícia de estudos mais recentes sobre preços nos mercados de chocolates.
} 
Elevações de preços que decorrem naturalmente da criação ou do aumento do poder de mercado pós-fusão podem ser contidas caso as sinergias geradas pela operação sejam qualitativa e quantitativamente suficientes. ${ }^{17}$

A despeito dos argumentos apresentados, o CADE entendeu que as sinergias alegadas por Nestlé e Garoto nāo bastavam para neutralizar os efeitos deletérios da operação proposta sobre a concorrência e sobre os consumidores de chocolates.

$\mathrm{Na}$ verdade, entendeu o órgão que muitas das eficiências argüidas sequer poderiam ser enquadradas nessa categoria ou admitidas para fins de elaboração de um balanço concorrencial de um ato de concentração. Após analisar detalhadamente cada um dos itens apontados pelas requerentes como geradores de reduções de custos após a operação, a conclusão do CADE foi no sentido de que somente poderiam ser computadas, para fins de uma análise antitruste, reduções de custos variáveis com (i) embalagens, (ii) fechamento de depósitos, e (iii) renegociação de frete.

Todas as demais eficiências argüidas foram descartadas, ${ }^{18}$ seja em virtude de nāo implicarem reduções de custos variáveis, seja em virtude de constituírem ganhos meramente pecuniários, ou por não serem específicas da operação ou, ainda, por não terem sido demonstradas por meios razoáveis, podendo ser alcançadas de outra forma menos restritiva à concorrência.

Ocorre que as eficiências aceitas pelo CADE representariam uma economia em torno de apenas $2 \%$ após a operação, percentual muito inferior àquele que, segundo os estudos realizados pelas próprias requerentes, evitariam elevaçōes de preços por parte da empresa fusionada (em torno de $12 \%$ ).

Assim, é correta a opinião contida nos votos vencedores, no sentido de que "torna-se claro que o nivel das eficiências que podem ser geradas pela operação, mesmo aceitando-se os valores estimados pelas Requerentes com todas as restrições apontadas, é insuficiente para impedir aumentos de prȩ̧os aos consumidores, que serão forçosamente prejudicados caso a operação seja autorizada pelo CADE" (trecho extraído do voto proferido pelo Conselheiro Thompson Andrade em 4.2.2004). ${ }^{19}$

\footnotetext{
Esse aspecto encontra-se diretamente relacionado à discussão que surgiu nos autos sobre a adequação do modelo de O. WILLIAMSON, proposto pelos pareceristas contratados pela Nestlé e pela Garoto, vis-à-vis ao modelo denominado price-standard, aplicado por Jorge FAGUNDES, parecerista contratado pela Kraft, segundo o qual uma operação restritiva da concorrência somente deveria ser aprovada caso produzisse uma redução de custos marginais tal que o novo preço a ser fixado pela empresa fusionada não fosse superior ao preço antes da operação, de modo que a fusāo não implicasse transferência de renda dos consumidores para os produtores (a esse respeito, ver FAGUNDES, op. cit.). Acabou prevalecendo nos votos vencedores a idéia de que o modelo de WILLIAMSON seria inadequado, no caso concreto, para aferir os impactos sobre o bem-estar social derivados da aquisição da Garoto pela Nestlé, com efeitos horizontais, por desconsiderar o problema da redistribuiçāo de renda inerente ao exercício de poder de mercado (e também a ineficiência $\mathrm{X}$ ).

18 A exemplo do que já havia ocorrido por ocasiāo do julgamento unânime do Ato de Concentração $\mathrm{n}^{\mathrm{o}}$ 08012.006976/2001-58 (G. Barbosa).

19 No mesmo sentido: "Comungo da mesma opiniāo do Relator que descarta várias das eficiências apresentadas. Gostaria apenas de lembrar que ao longo da instrução desse processo, o valor das eficiências apresentados nos três órgāos (SEAE, SDE, CADE) variou substancialmente. Lembro que estamos tratando de uma situação (análise
} 
A experiência internacional tem mostrado que a concentração do poder econômico, quando não compensada por eficiências distribuídas eqüitativamente com os consumidores ou usuários finais, gera efeitos deletérios para o mercado e para os consumidores. Nesse sentido, manifestou-se o Conselheiro Fernando Marques:

"Neste caso as eficiências aumentaram ao longo do processo, [...] não sendo igualmente acostado elemento que denote sua distribuição ao mercado e ao consumidor aumentando a concorrência e o bem-estar social..." (trecho extraído do voto vogal proferido pelo Conselheiro Fernando de Oliveira Marques em 4.2.2004).

Em suma, não constitui nenhuma novidade o fato de que uma empresa detentora de poder de mercado certamente irá exercê-lo, sendo certo que a empresa resultante da fusão entre a Garoto e a Nestlé teria condições para elevar lucrativamente os preços de seus produtos nos mercados relevantes de chocolates sob todas as formas e de coberturas de chocolate, em prejuizo dos consumidores, mesmo levando-se em consideração as eficiências geradas pela operação no mercado em tela. Foi justamente buscando evitar essa situação que o CADE, por 5 (cinco) votos a 1 (um), determinou a desconstituição total da operação.

\section{Consideraçōes sobre a adequação da solução estrutural global}

Após reconhecer que a consumação da compra da Garoto pela Nestlé permitiria o exercício de poder de mercado por parte da empresa resultante, e que as eficiências oriundas da referida operaçāo não seriam suficientes para coibir aumentos de preços e evitar prejuízos aos consumidores, o CADE determinou a desconstituição total do negócio, solução estrutural global envolvendo o trinômio planta, rede de distribuição e a marca Garoto (os quais deveriam ser alienados para um agente econômico que não detivesse mais do que $20 \%$ do mercado relevante de chocolates sob todas as formas).

A adoção de uma solução comportamental na espécie foi acertadamente afastada pelo CADE, por não atender os requisitos do $\$ 1^{\circ}$ do art. 54 da Lei 8.884/94.

Com efeito, entendeu o CADE não ser admissível a celebração de um Compromisso de Desempenho que permitisse que a Nestlé continuasse detendo ou, de qualquer forma, controlando os ativos relacionados ao setor de chocolates (inclusive as marcas dos produtos), anteriormente detidos pela Garoto. Nos termos do voto condutor do Conselheiro Relator Thompson de Almeida Andrade:

de eficiência) marcada por forte assimetria informacional, e que, portanto, o grau de exigência na sua comprovação deve ser o mais elevado possivel" (trecho extraído do voto vogal proferido pelo Conselheiro Cleveland Prates Teixeira em 4.2.2004). 
"Entendo que não cabe no presente caso adotar-se uma solução comportamental, pelos motivos que passo a expor:

Primeiro porque a solução estrutural tem sido reconhecida como a alternativa mais eficaz para eliminar os efeitos anticoncorrenciais decorrentes de altas concentrações em fusões ou aquisições.

$[\ldots]$

Além dessa predileção crescente pela solução estrutural como meio mais eficaz para eliminar efeitos decorrentes de altas concentrações, há que se observar ainda que não cabe aqui adotar a solução comportamental porque a nossa lei não permite que adotada a solução em casos como o presente. A celebração de compromisso de desempenho, prevista no art. 58 da Lei 8.884/94, é uma alternativa conferida ao $C A D E$ quando for verificado que determinada operação, embora potencialmente pre-

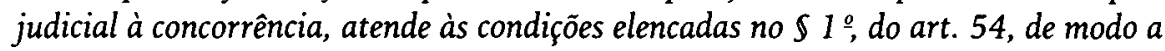
assegurar, pelo estabelecimento de metas e sob certas penas, a obrigação de que tais condições serão efetivamente cumpridas. Ora, como já demonstrado, a operação em

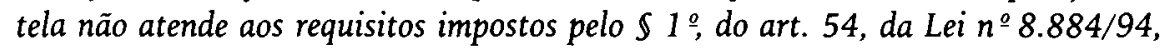
o que, portanto impõe ao CADE tão-somente a não aprovação do Ato e a adoção das medidas necessárias ao seu desfazimento" (voto proferido pelo Conselheiro Thompson Andrade em 4.2.2004). ${ }^{20}$

O posicionamento do CADE encontra-se em plena conformidade com as recomendações e diretrizes internacionais nesse campo, bem sintetizadas no trabalho conjunto do Banco Mundial e da Organização para a Cooperação e o Desenvolvimento Econômico (OCDE):

“o objetivo [da análise antitruste de concentraçōes] é simplesmente remover a ameaça anti-competitiva ao mercado. Os meios para atingir essa finalidade podem ser divididos em três categorias: prevenção da fusão em sua integralidade, dissolução total ou desconstituição da empresa fusionada; desinvestimento parcial de ativos ou operações, suficiente para eliminar os efeitos anti-competitivos enquanto a operação proposta é autorizada a prosseguir; e determinações regulando ou modificando a conduta da empresa fusionada para evitar os efeitos anti-competitivos temidos. Os dois primeiros remédios podem ser considerados estruturais, o terceiro comportamental. Os remédios estruturais sāo geralmente preferiveis. São mais efetivos no longo prazo e, igualmente importante, não requerem supervisão continuada ou regulação pela agência de concorrência. É fortemente recomendado que remédios estruturais sejam implementados antes da con-

20 No mesmo sentido, destaca-se o seguinte trecho do voto do Conselheiro Roberto Pfeiffer: "No caso concreto, nāo haveria: a) possibilidade de aprovação do ato, tendo em vista a ausência dos parâmetros legais que permitiriam tal aprovaçāo; b) conseqüentemente, estaria vedado ao CADE a possibilidade de utilizar compromisso de desempenho e; c) nāo há qualquer solução intermediária que pudesse ser lançada e que alcançasse os resultados de re-estabelecimento do padrão concorrencial de mercado, nāo sendo resolvida a questão com uma desconstituição parcial" (voto vogal do Conselheiro Roberto Pfeiffer, 05/02/2004, p. 17). 
sumação da fusão proposta. É difícil e moroso, e algumas vezes impossível, desfazer a fusāo depois que a mesma ocorreu". ${ }^{21}$

O CADE também avaliou a possibilidade de adotar uma solução estrutural parcial (venda de ativos, por exemplo), afastando-a por considerá-la ineficaz e pior sob a ótica concorrencial quando comparada à venda da Garoto como um todo. Nesse sentido:

"Diante dos fatos apresentados, procurei verificar se haveria alguma forma de adotar medidas estruturais que implicassem a desconstituição parcial da operação $e$ que, ao mesmo tempo, garantissem as condições mínimas de concorrência de forma a que o consumidor não fosse prejudicado. O que observei, entretanto, é que isso não seria possivel. A Garoto é uma empresa que tem um conjunto de atributos (marcas, fábricas, etc.) que é fundamental para garantir a concorrência. Dessa forma, entendo que o ideal é a sua manutenção como uma entidade coesa de competição, preservando o máximo de suas características" (trecho extraido do voto vogal do Conselheiro Cleveland Prates Teixeira, 4.2.2004). ${ }^{22}$

Na mesma direçāo caminha a jurisprudência norte-americana. Após anos de experiência na aplicação do Hart-Scott-Rodino Antitrust Improvements Act (HSR Act) de 1976, e tendo realizado uma revisão das decisões da Federal Trade Commission (FTC) norte-americana determinando desinvestimentos totais e parciais em diversos mercados, o Departamento de Concorrência da FTC elaborou estudo apontando, entre outras conclusões, que os desinvestimentos mais efetivos e bem-sucedidos foram aqueles envolvendo o negócio completo, ao invés de um conjunto de ativos, tangiveis ou intangiveis. ${ }^{23}$

21 Traduçāo livre de trecho do trabalho intitulado $A$ framework for the design and implementation of competition law and policy (World Bank, Washington, DC and Organisation for Economic Co-operation and Development, Paris, 1998, p. 53).

22 Da mesma forma: "as características do mercado demonstram de forma cabal a absoluta impropriedade de soluçōes parciais. Ficou bem demonstrada que a competitividade no mercado de chocolates sob todas as formas demanda a necessidade de um amplo portifolio de produtos, o que seria ameaçado caso, por exemplo, fosse determinada a alienação de apenas algumas marcas. Deste modo, na realidade, é o posicionamento da Garoto como um todo, com o seu elástico portifolio, que lhe permite uma posiçāo de disciplinamento do mercado evitando aumento de preços. O desmantelamento da sua linha de produtos (essencialmente coberturas e chocolates) que seria ocasionado por qualquer solução de desinvestimento parcial retiraria dela tal capacidade, tornando absolutamente inócua tal medida, que não evitaria a lesão à concorrência (trecho extraído do voto vogal do Conselheiro Roberto Pfeiffer, 04.02.04).

23 Destacam-se os seguintes trechos: " $\ldots$ divestiture of an on-going business is more likely to result in a viable operation than is divestiture of assets selected to facilitate entry. The general notion that the sale of an on-going business is more likely to be successful in establishing a competitor than the sale of less than an entire business seems intuitively obvious and is consistent with the reasons for Congressional concern about a lack of organic integrity of divested business" (p. 10); "divestitures can restore competition that would be lost as a result of a merger. Divestiture of an entire business is more likely to be successful than the divestiture of parts of a business" (p. 14); e "the most effective divestitures have been those of on-going businesses. Divestitures of narrow asset packages, even with some of the protections discussed above, create a greater risk that competition will not be restored, and thus must be carefully examined before they are accepted" (p. 38) (A Study of the Commission's divestiture Process, preparado pelo Staff do Bureau of Competition da Federal Trade Commission). 
Os limites da reestruturação em processos de análise antitruste de fusões e aquisiçōes são abordados em artigo de Robert PITOFSKY. ${ }^{24} \mathrm{O}$ autor observa que a FTC sempre esteve - e continuará - disposta a considerar propostas de reestruturação (quando a operação aprovada é distinta daquela inicialmente submetida, em virtude de desinvestimentos parciais, por exemplo), ainda que complexas, se for esperado que elas preservarão a concorrência. No entanto, consigna que é ônus dos requerentes da operação demonstrar a sua adequaçāo, já que possuem mais informaçōes sobre a sua indústria do que as autoridades.

No caso concreto, nenhuma reestruturação seria adequada, já que, conforme declarado pela Nestlé, "qualquer decisão de remeter ativos para outras unidades levaria 3 anos para ser reorganizada. A Garoto tem uma fábrica, não dez. É um monobloco: centro de distribuição, produção, fornecimento, administração". ${ }^{25}$ Tais aspectos foram comprovados pelo CADE ao analisar e reprovar, por maioria de votos, a proposta de desinvestimento das requerentes, em pedido de reconsideração à autarquia.

Desse modo, tem-se que a decisão do CADE foi tecnicamente a mais acertada para o caso analisado, representando não apenas o amadurecimento institucional do órgão, mas também e principalmente um importante passo no sentido do desenvolvimento da cultura da concorrência no Brasil. ${ }^{26} \mathrm{O}$ CADE, sob todos os aspectos, cumpriu as funções para as quais foi criado.

\footnotetext{
24 The nature and limits of restructuring in merger Review, Cutting Edge Antitrust Conference, Law Seminars International, New York, fev. 2000.

25 Declaraçāo do Diretor de Assuntos Corporativos da Nestlé ao jornal Valor Econômico, em 2 de fevereiro de 2004, comentando a possibilidade de o CADE determinar a venda de alguns ativos da Garoto a terceiros.

26 A esse respeito, vide "O Cade cumpriu sua obrigação: anulação da venda da Garoto é exercício de defesa da concorrência" (editorial do jornal O Estado de S. Paulo, 17.2.2004, p. A-3) e "Nestlé sem Garoto: a livre concorrência é entendida como aplicaçāo concreta da livre iniciativa, jamais sua negaçāo", por Afonso A. de Mello FRANCO NETO, Celso Fernandes CAMPILONGO e Ronaldo MACEDO JR. (Folha de S. Paulo, 3.3.2004, Opiniāo, p. A-3).
} 